\section{Greenhouse Growth of Marigolds in Three Leached Sources of Spent Mushroom Compost over a 3-Year Period}

\author{
John R. Young, ${ }^{1}$ \\ E. Jay Holcomb, and \\ Charles W. Heuser ${ }^{2}$
}

\begin{abstract}
Additional INDEX words. spent mushroom compost (SMC), growing media physical properties, Tagetes patula
\end{abstract}

Summary. Though high electrical conductivity (EC) levels are commonly held to be the primary limiting factor for using spent mushroom compost (SMC) as a growing substrate, EC can be reduced by leaching. This allowed SMC to be successfully used for growing plants. Leaching reduced EC of the substrate solution from as high of $30 \mathrm{dS} \cdot \mathrm{m}^{-1}$

$\left(\mathrm{mmhos} \cdot \mathrm{cm}^{-1}\right)$ to 2 to $3 \mathrm{dS} \cdot \mathrm{m}^{-1}$, a level acceptable for growing plants. The initial EC and container capacity determined the number of leachings and total volume of water required to lower EC of SMC substrates to acceptable levels. As the concentration of SMC was increased, a higher number of leachings or larger volume of water were required to adequately reduce EC levels. In trials spanning 2.5 years, SMC was effectively used as a substrate in the production of marigold (Tagetes patula) 'Yellow Girl'. Benefits to plant growth from SMC incorporation included a slow release of nutrients as the SMC decomposed and a good air-filled pore space/water-holding capacity when amended with a commercial nursery mix. From these trials, it is recommended that SMC be incorporated at rates of $25 \%$ to $50 \%$. It is not recom-

\footnotetext{
${ }^{1}$ Former graduate student, current address: 765 West Hamilton Ave., State College, PA 16801.

${ }^{2}$ Professor of floriculture and professor of ornamental horticulture, Department of Horticulture, 102 Tyson Building, Pennsylvania State University, University Park, PA 16802.
}

mended that SMC be used in concentrations over $50 \%$ because the EC may be too difficult to manage and the high levels of air-filled pore space of SMC. Though season may affect the initial EC level of SMC, such variation is minimized by leaching while differences in plant response are more likely to be attributed to environmental conditions. No differences in plant growth were observed among SMC sources.

S pent mushroom compost is material that has been previously used as a growing medium for mushroom production. The supply of SMC exceeds the current demand, and excess SMC is unsightly and nutrients leached from SMC are a potential pollutant.

Eames (1977) reported reduced plant growth and concluded that SMC had little potential for use in container crops. Lemaire and Dartigues (1985) concluded that "The mushroom compost can not be used alone because of its lack of stability, its low water availability, its high salinity and a neutral $\mathrm{pH}$ which may not be suitable to all growing plants".

However, for chrysanthemum (Chrysanthemum morifolium) and easter lily (Lilium longiflorum), the most commercially desirable plants were produced in a substrate of SMC and commercial mix in a $1: 1(\mathrm{vol} / \mathrm{vol})$ ratio when grown under greenhouse conditions (Dallon, 1988). In research using field soil, peat moss, limestone, and perlite in combination with either fresh SMC or SMC that had been aerobically composted for 6 to 12 weeks, chrysanthemum 'High Regard', tomato (Lycopersicon esculentum) 'Roadside Red' and marigold 'Dainty Marietta' seedlings were reported to grow faster and attain salable quality sooner in SMC-amended media (Rathier, 1982). Henny (1979 and 1980 ) reported no significant differences among dumbcane (Dieffenbachia), pilea (Pilea spp.), pothos (Epipremnum aureum), and podocarpus (Podocarpusmacrophyllus) grown in $100 \%$ aged SMC (9 months) with I SMC : l pine bark and l peat : 1 pine bark (vol/vol). However, peperomia (Peperomia spp.) growth was higher in $100 \%$ SMC than $50 \%$ SMC and was lower in the absence of SMC. Henny concluded that high quality foliage plants could be grown in substrates composed of up to $100 \%$ SMC. Broccoli (Brassica oleracea var. italica), lettuce (Lactuca sativa), tomato, and marigolds plants grown in aged SMC were of higher quality than those grown in fresh SMC (Lohr and Coffey, 1987).

High EClevels are the main obstacles to using fresh SMCin containerized growing substrates. The high EC of fresh SMC significantly exceeded the desired EC for a plant growing substrate (Lang, 1996). The ions most frequently present in SMC were potassium $\left(\mathrm{K}^{+}\right)$, calcium $\left(\mathrm{Ca}^{2+}\right)$, magnesium $\left(\mathrm{Mg}^{2+}\right)$, ammonium $\left(\mathrm{NH}_{4}^{+}\right)$, nitrate $\left(\mathrm{NO}_{3}^{-}\right)$, chloride $\left(\mathrm{Cl}^{-}\right)$and sulfate $\left(\mathrm{SO}_{4}^{-2}\right)$ (Dallon, 1987).

Chong and Hamersma (1997) have demonstrated that salts can be easily and effectively leached out of SMC-containing substrates with water. Plants grown in leached fresh SMC were similar to plants grown in weathered compost. However, effective utilization of SMC in container substrates required rapid leaching before or immediately following planting (Chong et al., 1991a). To effectively use SMC as a growing substrate, it must be leached and the volume of water needed must be determined.

Physical properties of components determine the effectiveness of growing substrates. Composts from five mushroom farms in Ontario, Canada had total porosities greater than the desired $50 \%$ and air capacities greater than the minimum $20 \%$ to $25 \%$ (Chong et al., 1991a). In addition, physical properties of fresh SMC must be determined and the variability of the SMC during different seasons must be determined.

The objectives of this research were 1) to determine the volume of water needed to reduce the EC in SMC-amended media to $2 \mathrm{dS} \cdot \mathrm{m}^{-1}$, and 2) to determine the physical properties of SMC and to determine the growth responses of marigold 'Yellow Girl' to SMC-containing substrates.

\section{Materials and methods}

Leaching study. SMC from three sources was collected and blended with a commercial nursery mix (CNM) (Hansen's Nursery, Sassamansville, Pa.) at rates of $0 \%, 25 \%, 50 \%, 75 \%$, and $100 \%$ by volume. The CNM was composed of fresh pine bark : sphagnum peatmoss : $0.6-\mathrm{cm}(0.25$-inch $)$ crushed stone $(3: 1: 1$ by vol). A total of 15 substrates were prepared. The sub- 
Table 1. Electrical conductivity of leaching fraction from three sources of spent mushroom compost (SMC) combined in various proportions with a commercial nurserymix.

\begin{tabular}{|c|c|c|c|c|}
\hline \multirow{2}{*}{$\begin{array}{l}\text { Leaching } \\
\text { no. }\end{array}$} & \multicolumn{4}{|c|}{ Electrical conductivity $\left(\mathrm{dS} \cdot \mathrm{m}^{-1}\right)$} \\
\hline & $25 \%$ SMC & $50 \%$ SMC & $75 \%$ SMC & $100 \%$ SMC \\
\hline 1 & 2.6 & 4.0 & 4.7 & 3.4 \\
\hline 2 & 2.9 & 4.1 & 5.5 & 6.1 \\
\hline 3 & 1.5 & 2.2 & 3.0 & 3.8 \\
\hline 4 & & 1.3 & 1.9 & 2.8 \\
\hline 5 & & & 1.6 & 1.9 \\
\hline 6 & & & & 1.6 \\
\hline Linear regression & ** & $* * *$ & $* * *$ & $* * *$ \\
\hline$R^{2}$ & 0.56 & 0.76 & 0.70 & 0.54 \\
\hline
\end{tabular}

${ }^{\mathrm{z}}$ Composed of fresh pine bark : sphagnum peatmoss : $0.6 \mathrm{~cm}(0.25$ inch $)$ crushed stone $(3: 1: 1$ by vol).

${ }^{* *},{ }^{* * *}$ Significant $\mathrm{F}$ test at the $P \leq 0.01$ or 0.001 , respectively.

strates were packed into a 7.6 -cm-diameter ( 3 inches) by $7.6-\mathrm{cm}$-long aluminum cylinder. Each cylinder was fitted with a plastic collar fashioned from the upper one-third of a $10.2-\mathrm{cm}$ (4-inch) round pot and a piece of cheese cloth was used to hold the substrate in the cylinder yet allow free flow of water. Each cylinder was placed in a Buchner funnel and aliquots of deionized water were poured evenly over the surface of the substrate until the EC of the leachate was determined to be less than $2 \mathrm{dS} \cdot \mathrm{m}^{-}$ ${ }^{1}$. The volume of water (one aliquot) used for leaching at each time for each substrate was $230,225,240,250$, and $250 \mathrm{~mL}(7.8,7.6,8.1,8.5$, and $8.5 \mathrm{fl}$ oz) for the $0 \%, 25 \%, 50 \%, 75 \%$, and $100 \%$ mixes, respectively. The leaching volumes represented the container capacity of each substrate as previously determined (data not shown). The EC of the leachate from each aliquot was measured.

Six replications of each substrate were tested and EC was regressed against number of leachings for the five substrates. Analyses were conducted using Minitab 12 (Minitab, 1997).
Chemical and physical analysis. SMC from three sources was collected and soilless media analyses were conducted by Penn State Analytical Services Laboratory on each of the SMC samples using the saturated media extract procedure.

Each of the three SMC sources was mixed with the commercial substrate previously described at a rate of at $0 \%, 25 \%, 50 \%, 75 \%$, and $100 \%$. Bulk density, air-filled pore space and water-holding capacity were determined as outlined by Fonteno et al. (1981) and Fonteno and Bilderback (1993). Physical properties were regressed against percent SMC in the substrate (Minitab, 1997).

Marigold culture. Marigold 'Yellow Girl' was grown in substrates previously described in a series of seven trails. The trials were Fall 1997 planted on week 42, Spring 1998 planted on week 11, Summer 1998 planted on week 23, Fall 1998 planted on week 38, Spring 1999 planted on week 10, Summer 1999 planted on week 20 and Fall 1999 planted on week 47.

SMC from three mushroom growers was collected seven times over a 2 - year period. All trials were conducted in Penn State University Horticulture greenhouses. Each substrate was replicated three times with 12 to 15 subsamples within each replication. One marigold seedling, at the first true leaf stage [about $2.5 \mathrm{~cm}$ ( 1 inch) in height], was planted into each 10.2 $\mathrm{cm}[0.6-\mathrm{L}(0.16-\mathrm{gal})]$ container filled with substrate. After planting, each container was leached with three to four aliquots of water to reduce EC to a pour-through level below $2 \mathrm{dS} \cdot \mathrm{m}^{-1}$. The marigolds were fertilized as needed with Peter's 21-7-7 Acid Special fertilizer $(2 \mathrm{lN}-3.1 \mathrm{P}-5.8 \mathrm{~K}$; The Scotts Co., Marysville, Ohio) at $250 \mathrm{mg} \cdot \mathrm{L}^{-1}$ (ppm) nitrogen. Greenhouse temperatures were maintained at a minimum of $16^{\circ} \mathrm{C}\left(60^{\circ} \mathrm{F}\right)$ night and ventilation began at $21^{\circ} \mathrm{C}\left(70^{\circ} \mathrm{F}\right)$. After 8 weeks of growth, plants were cut off at the soil line, and fresh and dry shoot weights were recorded. Fresh and dry weights were regressed against percent SMC in the substrate (Minitab, 1997).

\section{Results and discussion}

Leaching study. The 0\% SMC substrate required no leaching since the initial EC was below $2 \mathrm{dS} \cdot \mathrm{m}^{-1}$ (data not presented). For SMC-containing substrates, the EC of the first leachate was lower than that of the second while the EC of the third and subsequent leachings decreased (Table 1). The number of times leaching was repeated and total amount of water required to reduce the $\mathrm{EC}$ of any given substrate below $2 \mathrm{dS} \cdot \mathrm{m}^{-1}$ was similar for each SMC source (data not presented). When the results from the three sources were combined, there was a significant linear relationship between EC and the number of leachings. On average, three leaching aliquots were required to reduce the

Table 2. Chemical analysis of commercial nursery mix (CNM) and spent mushroom compost (SMC ${ }^{\mathrm{z}}$ ) from three sources. ${ }^{\mathrm{y}}$ Analysis conducted by Penn State Analytical Services Laboratory on a composite sample of each substrate.

\begin{tabular}{|c|c|c|c|c|c|c|c|}
\hline \multirow[b]{2}{*}{ Substrate } & \multirow[b]{2}{*}{$\mathbf{p H}$} & \multirow{2}{*}{$\begin{array}{c}\text { EC } \\
\left(\mathrm{dS} \cdot \mathrm{m}^{-1}\right) \\
\end{array}$} & \multicolumn{5}{|c|}{ Nurient ${ }^{x}\left[\mathbf{m g} \cdot L^{-1}(p p m)\right]$} \\
\hline & & & $\mathrm{NO}_{3}-\mathrm{N}$ & $\mathbf{P}$ & $\mathbf{K}$ & $\mathrm{Ca}$ & Mg \\
\hline CNM & 7.7 & 0.6 & 0.5 & 1.2 & 54 & 39 & 19 \\
\hline SMC-Source 1 & 8.3 & 25.6 & 23.4 & 28.0 & 7403 & 1108 & 376 \\
\hline SMC-Source 2 & 8.3 & 18.4 & 12.8 & 16.6 & 4583 & 994 & 394 \\
\hline SMC-Source 3 & 8.1 & 16.1 & 26.3 & 17.4 & 3824 & 1212 & 389 \\
\hline Optimumw & $5.5-6.5$ & $2.0-3.0$ & $100-200$ & $6-9$ & $100-200$ & $150-250$ & $40-80$ \\
\hline
\end{tabular}

${ }^{\mathrm{z} S M C}$ was obtained from three mushroom growers.

yComposed of fresh pine bark : sphagnum peatmoss : $0.6 \mathrm{~cm}(0.25$ inch $)$ crushed stone $(3: 1: 1$ by vol $)$.

${ }^{x} \mathrm{EC}=$ electrical conductivity $\left(\mathrm{dS} \cdot \mathrm{m}^{-1}=\mathrm{mmhos} \cdot \mathrm{cm}^{-1}\right), \mathrm{NO}_{3}-\mathrm{N}=$ nitrate nitrogen, $\mathrm{P}=$ phospohorus, $\mathrm{K}=$ potassium, Ca $=\mathrm{calcium}, \mathrm{Mg}=\mathrm{magnesium}$.

${ }^{w}$ Optimum range for saturated media extract from Lang (1996). 
Table 3. Bulk density in relationship to increasing amounts of three sources of spent mushroom compost $\left(S_{M C}{ }^{z}\right)$ mixed with a commercial nursery mix. ${ }^{y}$

\begin{tabular}{|c|c|c|c|c|}
\hline \multirow[b]{2}{*}{ Substrate } & \multicolumn{4}{|c|}{ Bulk density $\left(\mathrm{g} \cdot \mathrm{cm}^{-1}\right)$} \\
\hline & All sources sou $^{x}$ & Source 1 & Source 2 & Source 3 \\
\hline $0 \% \mathrm{SMC}$ & & 0.49 & 0.49 & 0.49 \\
\hline $25 \% \mathrm{SMC}$ & 0.43 & 0.45 & 0.43 & 0.42 \\
\hline $50 \% \mathrm{SMC}$ & 0.36 & 0.37 & 0.37 & 0.34 \\
\hline $75 \%$ SMC & 0.28 & 0.30 & 0.28 & 0.28 \\
\hline $100 \% \mathrm{SMC}$ & 0.19 & 0.22 & 0.17 & 0.19 \\
\hline Mix & $* * *$ & $* * *$ & $* * *$ & $* * *$ \\
\hline Source & $\star * *$ & & & \\
\hline Mix $\times$ source & NS & & & \\
\hline Linear & $\star * *$ & $\star * *$ & $\star * *$ & $* * *$ \\
\hline Quadratic & $*$ & * & $* * *$ & NS \\
\hline
\end{tabular}

${ }^{\mathrm{z} S M C}$ was obtained from three mushroom growers.

y Composed of fresh pine bark : sphagnum peatmoss : $0.6 \mathrm{~cm}(0.25$ inch $)$ crushed stone $(3: 1: 1$ by vol).

"Analysis of variance (ANOVA) and regression for the "all sources" category was only conducted on the SMC containing mixes since only one set of $0 \%$ SMC was made and including it in an overall analysis would falsely weight the variation. This one set of $0 \%$ SMC was used in the ANOVA and regression for mixes made with a particular source (Sourcel, Source 2, or Source 3).

Ns, ${ }^{* * *, * *, *}$ Nonsignificant or significant $\mathrm{F}$ test at the $P \leq 0.001,0.01$ or 0.05 , respectively.

Table 4. Average percentage of air-filled pore space (vol/vol) in relationship to increasing amounts of three sources of spent mushroom compost $\left(S_{M} C^{z}\right)$ mixed with a commercial nurserymix. . $^{\text {t }}$

\begin{tabular}{|c|c|c|c|c|}
\hline \multirow[b]{2}{*}{ Substrate } & \multicolumn{4}{|c|}{ Air-filled pore space (\%) } \\
\hline & All sources sou $^{x}$ & Source 1 & Source 2 & Source 3 \\
\hline $0 \% \mathrm{SMC}$ & & 13.2 & 13.2 & 13.2 \\
\hline $25 \% \mathrm{SMC}$ & 13.4 & 14.7 & 12.5 & 13.2 \\
\hline $50 \% \mathrm{SMC}$ & 14.0 & 15.2 & 11.7 & 15.1 \\
\hline $75 \% \mathrm{SMC}$ & 15.8 & 11.3 & 15.1 & 20.4 \\
\hline $100 \% \mathrm{SMC}$ & 19.0 & 17.1 & 25.9 & 13.7 \\
\hline Mix & $* * *$ & NS & $* * *$ & $* * *$ \\
\hline Source & NS & & & \\
\hline Mix $\times$ source & $* * *$ & & & \\
\hline Linear & $* * *$ & NS & $* * *$ & NS \\
\hline Quadratic & NS & NS & $\star \star *$ & * \\
\hline
\end{tabular}

${ }^{\mathrm{z} S M C}$ was obtained from three mushroom growers.

y Composed of fresh pine bark : sphagnum peatmoss : $0.6 \mathrm{~cm}(0.25$ inch $)$ crushed stone (3:1:1 by vol).

"Analysis of variance (ANOVA) and regression for the "all sources" category was only conducted on the SMCcontaining mixes since only one set of $0 \%$ SMC was made and including it in an overall analysis would falsely weight the variation. This one set of $0 \%$ SMC was used in the ANOVA and regression for mixes made with a particular source (Source 1, Source 2, or Source 3).

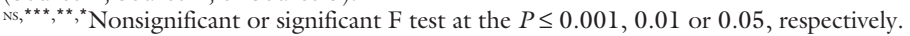

EC to $2 \mathrm{dS} \cdot \mathrm{m}^{-1}$ or less for a $25 \% \mathrm{SMC}$ mixture, four for $50 \%$, five for $75 \%$ and six for $100 \%$ SMC.

In other studies the EC of SMC was easily lowered by leaching with water (Chong et al., 1991b). Chong recommended that three aliquots of water equal to the volume of the container would easily leach the soluble salts from potted SMC. We found a leaching requirement ranging from three to six aliquots depending on the amount of SMC in the mix.

Chemical and physical analySIS STUDY. A soilless media analysis of SMC revealed high $\mathrm{K}, \mathrm{Ca}, \mathrm{Mg}$, and $\mathrm{P}$ levels of $20,10,3$, and 2 times higher, respectively, than optimum levels (Table 2) recommended by Lang, (1996). Nitrate content was lower than optimum (Table 2). As SMC decomposes over time, it releases additional nutrients (Lemaire and Dartigues 1985). When managed properly, this nutrient release can supplement the normal fertilizer regime, which may reduce the need to add fertilizers to the growing systems.

The $\mathrm{pH}$ of SMC, between 8.1 and 8.3 , was substantially higher than optimum. All plants have an optimum $\mathrm{pH}$ range and most plants grow well in the range of 5.5 to 6.5 . The reason for the high $\mathrm{pH}$ of SMC is probably re- lated to raw material inputs for mushroom substrate production which may include horse manure, chicken manure, and limestone chips (Schisler, 1982).

Bulk density was lowest at 100\% SMC and increased as the amount of SMC decreased. (Table 3). Bulk density increased in a linear manner by about $0.24 \mathrm{~g} \cdot \mathrm{cm}^{-3}$ from $100 \%$ SMC to $25 \%$ SMC and each SMC source showed the same trend. The linear component accounted for no less than 26 times the amount of variation contributed by the quadratic component. This demonstrates that the relationship was primarily linear. The commercial nursery mix had crushed stone as one of the mix components which explains why it had a high bulk density. The bulk densities obtained for SMC in this study were similar to those found by Lohr et al. (1984).

Air-filled pore space was significantly affected by substrate except for source three (Table 4). Average airfilled pore space increased $6 \%$ from $100 \%$ CNM to $100 \%$ SMC. When data were combined, SMC source was not significant. When each source was analyzed separately, the percent of SMC was nonsignificant for Source 1 but was for Sources 2 and 3. The variation in air-filled pore space for all sources was significant and the linear component accounted for nine times the amount of variation according to the sums of squares. Increasing proportions of SMC increased air-filled pore space.

On average, the highest container capacity was achieved between 50\% and $75 \%$ SMC (Table 5 ). In the overall analysis of variance (ANOVA) of container capacity, there was a substrate by source interaction. However, in all but one group of substrates from an individual source, substrate did contribute significantly. Both SMC source and the interaction of substrate and source significantly impacted container capacity. There was no linear or quadric response.

Water-holding capacity, for unamended SMC determined in this study and averaged over three sources was $63.2 \%$ which was identical to the container capacity found by Lohr et al. (1984). The percent of SMC was not significantly related to container capacity for Source 1, but was significant for Source 2 and Source 3. In general, the container capacity increased as the 
Table 5. Average container capacity ${ }^{z}$ in relationship to increasing amounts of three sources of spent mushroom compost $\left(S M C^{y}\right)$ mixed with a commercial nursery mix. ${ }^{x}$

\begin{tabular}{lcccc}
\hline & \multicolumn{4}{c}{ Water-filled pore space (\%) } \\
\cline { 2 - 5 } Substrate & All sources $^{\mathbf{x}}$ & Source 1 & Source 2 & Source 3 \\
\hline 0\% SMC & & 59.0 & 59.0 & 59.0 \\
$25 \%$ SMC & 64.0 & 65.0 & 63.4 & 63.6 \\
$50 \%$ SMC & 65.0 & 65.9 & 66.3 & 62.7 \\
$75 \%$ SMC & 65.1 & 67.3 & 66.1 & 62.2 \\
100\% SMC & 63.2 & 64.6 & 56.2 & 68.7 \\
Mix & NS & NS & $* * *$ & $* * *$ \\
Source & $* *$ & & & \\
Mix x Source & $* * *$ & $*$ & NS & $* *$ \\
Linear & NS & $*$ & $* * *$ & NS \\
Quadratic & NS & & & \\
\hline
\end{tabular}

zPercentage of water-filled pore space ( $\mathrm{vol} / \mathrm{vol}$ ).

ySMC was obtained from three mushroom growers.

${ }^{\mathrm{x}}$ Composed of fresh pine bark : sphagnum peatmoss : $0.6 \mathrm{~cm}(0.25$ inch $)$ crushed stone $(3: 1: 1$ by vol $)$

"Analysis of variance (ANOVA) and regression for the "all sources" category was only conducted on the SMC containing mixes since only one set of $0 \%$ SMC was made and including it in an overall analysis would falsely weight the variation. This one set of $0 \% \mathrm{SMC}$ was used in the ANOVA and regression for mixes made with a particular source (Source 1, Source 2, or Source 3).

Ns, ${ }^{* * *},{ }^{* *},{ }^{*}$ Nonsignificant or significant $\mathrm{F}$ test at the $P \leq 0.001,0.01$ or 0.05 , respectively.

proportion of SMC increased to a maximum between $50 \%$ and $75 \%$ SMC. Further increase in SMC caused a reduction in water-holding capacity. SMC from Source 2 had a quadratic response while for Source 1 the response was linear. Although the container capacity of SMC from the sources had significant differences, the changes in container capacity were minimal. A reduction in container capacity has the practical implication that those media with reduced container capacity require more frequent irrigation. It seems likely that SMC from various sources could be irrigated in a similar manner.

To summarize, lower bulk densities and higher air-filled pore spaces are achieved in direct proportion to increasing percentages of SMC while water-filled pore space is greatest at $50 \%$ to $75 \%$ SMC. Based on physical properties determined in this work, it is suggested that desirable percentage of SMC would be between $25 \%$ and $75 \%$.

MARIGold RESPONSE. In marigold 'Yellow Girl' trials, the percentage of SMC in the mix had a significant effect on both plant fresh and dry weight. The source of SMC was significant in all trials except Trial 6 where the interaction could not be measured due to plant loss in one treatment and for fresh weight in Trial 1 (Tables 6 and 7). In all trials except Fall 1999, plant dry weight increased as percent SMC increased to $75 \%$. There was a subsequent decrease in plant dry weight of plants grown in 100\% SMC. In Fall, 1999, plant dry weight decreased as SMC concentration increased (Table 6). A similar pattern was observed for plant fresh weight except for the quadratic response in Fall 1999 Table (7).

Plants with the highest fresh and dry weight were grown at SMC percentages of $25 \%$ to $75 \%$. SMC had high EC before leaching and there may have been residual salts in the substrate which may explain the small size of plants grown in the $100 \%$ SMC. SMC based mixes have the advantage of a nutrient release over time because of SMC decomposition that supplements the basic fertilizer solution. The combination of SMC and CNM had a higher water holding capacity and thus did not dry as rapidly as other substrates (Lemaire and Dartigues 1985). We observed a reduction in the volume of the media over time with increasing SMC concentrations; however, the reduction was not quantified. Therefore, over one full growing season, both $75 \%$ and $100 \%$ SMC substrates have a great enough volume reduction that they should probably be excluded as viable options (Chong, 1994, Chong et al. 1994, Chong et al., 1991a). Therefore, substrates between $25 \%$ and $50 \%$ SMC are recommended for plant production.

The final objective of these trials was to determine whether or not different sources of SMC produced differences in plant response. When considering all data from all sources and trials, source did not have a statistically significant impact. However, when data

Table 6. Dry weight ${ }^{\mathrm{z}}$ of marigold 'Yellow Girl' grown in spent mushroom compost (SMC) or substrates composed of SMC and a commercial nursery mix ${ }^{y}$ from Fall 1997 through Fall 1999 in Pennsylvania State Horticulture greenhouses, University Park.

\begin{tabular}{|c|c|c|c|c|c|c|c|c|}
\hline \multirow[b]{2}{*}{ Substrate } & \multirow[b]{2}{*}{ df } & \multicolumn{7}{|c|}{ Dry wt (g) } \\
\hline & & $\begin{array}{c}\text { Trial 1 } \\
\text { Fall1997 }\end{array}$ & $\begin{array}{c}\text { Trial } 2 \\
\text { Spring } 1998\end{array}$ & $\begin{array}{c}\text { Trial 3 } \\
\text { Summer } 1998\end{array}$ & $\begin{array}{c}\text { Trial } 4 \\
\text { Fall } 1998\end{array}$ & $\begin{array}{c}\text { Trial } 5 \\
\text { Spring } 1999\end{array}$ & $\begin{array}{c}\text { Trial } 6 \\
\text { Summer } 1999\end{array}$ & $\begin{array}{c}\text { Trial } 7 \\
\text { Fall } 1999\end{array}$ \\
\hline $0 \% \mathrm{SMC}$ & & 0.4 & 2.2 & 1.8 & 5.5 & 3.1 & 1.3 & 7.9 \\
\hline $25 \% \mathrm{SMC}$ & & 0.6 & 5.4 & 3.7 & 4.9 & 3.8 & 2.8 & 6.3 \\
\hline $50 \% \mathrm{SMC}$ & & 0.7 & 6.4 & 2.3 & 5.8 & 4.7 & 3.7 & 7.2 \\
\hline 75\% SMC & & 0.4 & 6.2 & 2.1 & 4.9 & 3.1 & 3.3 & 6.3 \\
\hline $100 \%$ SMC & & 0.1 & 4.1 & 1.3 & 3.5 & 1.9 & 2.5 & 5.2 \\
\hline \multicolumn{9}{|c|}{ Analysis of variance } \\
\hline Source & 2 & NS & $* *$ & $* * *$ & $* * *$ & $* * *$ & $* *$ & $* * *$ \\
\hline Mix & 4 & $* * *$ & $* * *$ & $* * *$ & $* * *$ & $* * *$ & $* * *$ & $* * *$ \\
\hline Source $\times$ mix & 8 & * & * & $* * *$ & $* * *$ & $* * *$ & $* * *$ & \\
\hline Linear & 1 & $* * *$ & $* * *$ & $* * *$ & $* * *$ & $* * *$ & $* * *$ & $* * *$ \\
\hline Quadratic & 1 & $* * *$ & $* * *$ & $* * *$ & $* * *$ & $* * *$ & $* * *$ & NS \\
\hline
\end{tabular}

${ }^{\mathrm{z}} 1.0 \mathrm{~g}=0.04 \mathrm{oz}$.

yComposed of fresh pine bark : sphagnum peatmoss : $0.6 \mathrm{~cm}(0.25$ inch $)$ crushed stone $(3: 1: 1$ by vol $)$.

Ns, ${ }^{* * *},{ }^{* *},{ }^{*}$ Nonsignificant or significant $F$ test at the $P \leq 0.001,0.01$ or 0.05 , respectively. 
Table 7. Fresh weight $(\mathrm{g})^{\mathrm{z}}$ of marigold 'Yellow Girl' grown in spent mushroom compost (SMC) or substrates composed of SMS and commercial nursery mix ${ }^{y}$ from the Fall 1997 through Fall 1999 in Pennsylvania State Horticulture greenhouses, University Park.

\begin{tabular}{|c|c|c|c|c|c|c|c|c|}
\hline \multirow[b]{2}{*}{ Substrate } & \multirow[b]{2}{*}{ df } & \multicolumn{7}{|c|}{ Fresh wt (g) } \\
\hline & & $\begin{array}{c}\text { Trial 1 } \\
\text { Fall1997 }\end{array}$ & $\begin{array}{c}\text { Trial } 2 \\
\text { Spring } 1998\end{array}$ & $\begin{array}{c}\text { Trial 3 } \\
\text { Summer } 1998 \\
\end{array}$ & $\begin{array}{c}\text { Trial } 4 \\
\text { Fall } 1998 \\
\end{array}$ & $\begin{array}{c}\text { Trial } 5 \\
\text { Spring } 1999 \\
\end{array}$ & $\begin{array}{c}\text { Trial } 6 \\
\text { Summer } 1999 \\
\end{array}$ & $\begin{array}{c}\text { Trial } 7 \\
\text { Fall } 1999 \\
\end{array}$ \\
\hline $25 \% \mathrm{SMC}$ & & 6.9 & 50.9 & 28.8 & 45.0 & 31.5 & 22.0 & 58.5 \\
\hline $50 \% \mathrm{SMC}$ & & 6.9 & 59.2 & 21.5 & 46.1 & 29.4 & 26.6 & 62.8 \\
\hline $75 \% \mathrm{SMC}$ & & 4.2 & 59.1 & 16.8 & 39.2 & 23.0 & 26.7 & 55.4 \\
\hline Source & 2 & NS & ** & *** & ** & $* * *$ & $* * *$ & $* * *$ \\
\hline Mix & 4 & $* * *$ & $* * *$ & $* * *$ & $* * *$ & $* * *$ & $* * *$ & $* * *$ \\
\hline Source $\times$ mix & 8 & NS & * & $* * *$ & $* * *$ & $* * *$ & $* * *$ & \\
\hline Linear & 1 & $* * *$ & $* * *$ & $* * *$ & $* * *$ & $* * *$ & $* * *$ & $* * *$ \\
\hline Quadratic & 1 & $* * *$ & $* * *$ & $* * *$ & $* * *$ & $* * *$ & $* * *$ & $* *$ \\
\hline
\end{tabular}

were analyzed by trial, SMC source was significant except for Trial 1 (Tables 6 and 7). There was, however, no consistent pattern that SMC from one source produced larger plants than another source. The aeration of the SMC and the water-holding capacity of the SMC were not affected by source of SMC, but the bulk density was affected. Even though statistical significance of SMC source was determined in individual trials, it is reasonable for a grower to expect similar results in plant response to different sources of SMC.

\section{Conclusions}

In summary, SMC can be effectively used as a potted substrate component in the production of marigold. It is not recommended that SMC be used in concentrations over $50 \%$ because the soluble salt content may be too difficult to manage, and the reduced water-holding capacity associated with high concentrations of SMC. Though season may affect the initial soluble salt composition of SMC, such variation is most likely minimized by leaching while differences in plant response are more likely to be attributed to environmental conditions. Finally, though some statistical differences do exist, different SMC sources tend to produce plants of similar quality and size.

\section{Literature cited}

Chong, C. 1994. Bark- and peat-amended spent mushroom compost for container- ized culture of shrubs. HortScience 29:781-784.

Chong, C. and B. Hamersma. 1997. Container growing with spent mushroom compost. Mushroom News 45(11):12-14.

Chong, C, R.A. Cline, and D.L. Rinker. 1991b. Rapid leaching of salts key to successful plant growth in SMC potting mixes. Mushroom News 39(10):12, 13

Chong, C, R.A. Cline, and D.L. Rinker. 1994. Bark-and peat-amended spent mushroom compost for containerized culture of shrubs. HortScience 29:781-784.

Chong, C, R.A. Cline, D.L. Rinker, and B. Hamersma. 1991a. An overview of reutilization of spent mushroom compost in nursery container culture. Landscape Trades (Dec.):14-17.

Dallon, Jr., J. 1987. Effects of spent mushroom compost on the production of greenhouse-grown crops. Combined Proc. Intl. Plant Propagators Soc. 37:323-326.

Dallon, J., Jr. 1988. Physical and chemical characteristics of spent mushroom compost. Combined Proc. Intl. Plant Propagators Soc. 38:590-593.

Eames, A.G. 1977. Could spent mushroom compost be used for container shrubs. Mushroom J. 52:114.

Fonteno, W.C. and T.E. Bilderback. 1993. Impact of hydrogel on physical properties of coarse structured horticultural substrates. J. Amer. Soc. Hort. Sci. 118:217-222.

Fonteno, W.C., D.K. Cassel, and R.A. Larson. 1981. Physical properties of three container media and their effect on poinsettia growth. J. Amer. Soc. Hort. Sci. 106:736-741.
Henny, B.K.. 1979. Production of six foliage crops in spent mushroom compost potting mixes. Fla. State Hort. Soc. 92:330332.

Henny, B.K.. 1980. Spent mushroom compost-A possible mix component. Foliage Dig. 2(12):14-15.

Lang, H.J. 1996. Growing media testing and interpretation, p. 123-139. In: D.W. Reed (ed.). Water, media, and nutrition for greenhouse crops. Ball Publ., Batavia, Ill.

Lemaire, F. and A. Dartigues. 1985. Properities of substrate made with spent mushroom compost. Acta Hort. 172:1329

Lohr, V., S.H. Wang, and J.D. Wolt. 1984. Physical and chemical characteristics of fresh and aged spent mushroom compost. HortScience 19:681-683.

Lohr, V. and D.L. Coffey. 1987. Growth responses of seedlings to varying rates of fresh and aged spent mushroom compost. HortScience 22:913-915.

Minitab, 1997. Minitab statistical software. Minitab 12. Minitab, Inc., State College, $\mathrm{Pa}$.

Rathier, T.M. 1982. Spent mushroom compost for greenhouse crops. Foliage Dig. 5:11-12.

Schisler, L.C. 1982. Biochemical and mycological aspects of mushroom composting, p 3-10. In P. Wuest (ed.). Penn State handbook for commercial mushroom growers. Pa. State Univ., Univ. Park. 